\title{
On the use of radon for quantifying the effects of atmospheric stability on urban emissions
}

\author{
S. D. Chambers, A. G. Williams, J. Crawford, and A. D. Griffiths \\ Australian Nuclear Science and Technology Organisation, Locked Bag 2001, Kirrawee DC, NSW 2232, Australia \\ Correspondence to: S. D. Chambers (szc@ansto.gov.au)
}

Received: 1 August 2014 - Published in Atmos. Chem. Phys. Discuss.: 8 October 2014

Revised: 5 December 2014 - Accepted: 19 December 2014 - Published: 2 February 2015

\begin{abstract}
Radon is increasingly being used as a tool for quantifying stability influences on urban pollutant concentrations. Bulk radon gradients are ideal for this purpose, since the vertical differencing substantially removes contributions from processes on timescales greater than diurnal and (assuming a constant radon source) gradients are directly related to the intensity of nocturnal mixing. More commonly, however, radon measurements are available only at a single height. In this study we argue that single-height radon observations should not be used quantitatively as an indicator of atmospheric stability without prior conditioning of the time series to remove contributions from larger-scale "nonlocal" processes. We outline a simple technique to obtain an approximation of the diurnal radon gradient signal from a single-height measurement time series, and use it to derive a four category classification scheme for atmospheric stability on a "whole night" basis. A selection of climatological and pollution observations in the Sydney region are then subdivided according to the radon-based scheme on an annual and seasonal basis. We compare the radon-based scheme against a commonly used Pasquill-Gifford (P-G) type stability classification and reveal that the most stable category in the $\mathrm{P}-\mathrm{G}$ scheme is less selective of the strongly stable nights than the radon-based scheme; this lead to significant underestimation of pollutant concentrations on the most stable nights by the $\mathrm{P}-\mathrm{G}$ scheme. Lastly, we applied the radon-based classification scheme to mixing height estimates calculated from the diurnal radon accumulation time series, which provided insight to the range of nocturnal mixing depths expected at the site for each of the stability classes.
\end{abstract}

\section{Introduction}

The concentrations of gaseous and particulate pollutants in the atmosphere are governed by the rate at which they are emitted from their respective sources, lost by various sink mechanisms (including surface deposition and in situ chemical transformations), and characteristics of the atmospheric volume into which they mix (e.g. Veleva et al., 2010; Perrino et al., 2001, 2008; Avino et al., 2003; Duenas et al., 1996). This "mixing volume" (or mixing depth) changes diurnally over land, typically reaching maximum values early in the afternoon, and minimum values immediately prior to sunrise. In the simplest of cases (cloud-free), daytime mixing depth is determined primarily by the combined strength of convective turbulence (thermal circulations driven by solar heating of the Earth's surface) and mechanical mixing (related to wind speed and surface roughness). Nocturnal mixing depth, on the other hand, results from a balance between mechanical mixing and its suppression by thermal stratification in the lower atmosphere (e.g. Collaud Coen et al., 2014; Williams et al., 2013; Stull, 1988).

During winter in Sydney, as for many urban centres, accumulated domestic heating emissions combine with exhaust from peak-hour traffic in the shallow morning inversion layer, resulting in "brown haze" and pollutant levels that can exceed threshold guidelines (e.g. Hinkley et al., 2008; Gupta et al., 2007; Corbyn, 2005; Duc et al., 2000; Leighton and Spark, 1997; Liu et al., 1996). In summer, however, photochemical pollution events are more common; their severity linked to prevailing winds and cloudiness (Hart et al., 2006; Leslie and Speer, 2004; Azzi and Johnson, 1994; Hawke and Iverach, 1974). Clearer understanding of the processes that lead to haze or smog exceedance events, as well as an ability to quantify their magnitude, is important for assessing po- 
tential health impacts on residents, as well as identifying the need for, and evaluating the efficacy of, emissions mitigation strategies.

The term "atmospheric stability" - sometimes used synonymously with mixing depth - has been closely linked to pollution exceedance episodes in many urban centres (e.g. Grange et al., 2013; Ji et al., 2012; Perrino et al., 2008; Desideri et al., 2006; Avino et al., 2003; Duenas et al., 1996). Numerous measures of atmospheric stability have been devised and applied with varying degrees of efficacy. The most accurate of these measures are based on the values of, or ratios between, the near-surface temperature and wind speed gradients or their turbulent flux counterparts (Richardson number, Obukhov length, Turbulence kinetic energy etc.; Foken, 2006; Mahrt, 1999; Leach and Chandler, 1992). However, since these approaches are complex, expensive and labour intensive, they are also the least common, and often restricted to the duration of specific research campaigns. More widely used measures such as the PasquillGifford radiation and turbulence based stability classification schemes (Pasquill, 1961; Turner, 1964; Pasquill and Smith, 1983; Venkatram, 1996; USEPA, 2007), designed to be determined from routinely available climatological observations, are understandably less representative and versatile. Furthermore, the interpretation of micrometeorological or climatological observations necessary for all of these techniques is obfuscated by variability due to the effects of a variety of mesoscale motions operating in the nocturnal boundary layer, including local drainage flows, nocturnal jets, and intermittent turbulence (e.g. see review in Williams et al., 2013).

Recently, a growing number of investigators have begun exploiting the virtues of Radon-222 (radon) as a comparatively simple and economical means of quantitatively gauging atmospheric stability or mixing depth (Wang et al., 2013; Zhang et al., 2012; Xia et al., 2011; Perrino et al., 2001, 2008; Desideri et al., 2006; Galmarini, 2006; Acker et al., 2006; Sesana et al., 2003 and references therein; Duenas et al., 1996; Febo et al., 1996; Porstendörfer et al., 1991; Fujinami and Esaka, 1987). Radon is an unreactive, poorly soluble, radioactive gas $\left(t_{0.5}=3.82 d\right)$ that is emitted naturally from ice-free, unsaturated terrestrial surfaces at a rate that varies slowly both geographically and temporally $(0.72-$ 1.2 atoms $\mathrm{cm}^{-2} \mathrm{~s}^{-1}$; Turekian et al., 1977; Lambert et al., 1982; Jacob et al., 1997) and is two orders of magnitude greater than from open bodies of water (Wilkening and Clements, 1975; Schery and Huang, 2004). The half-life of radon is sufficiently long that it can be assumed to be an approximately conservative tracer over the course of a single night, while being short enough that it does not accumulate in the atmosphere and typically exhibiting an order of magnitude gradient between the atmospheric boundary layer (ABL) and the lower troposphere. This combination of physical characteristics makes radon a quantitative proxy for the effects (outcomes) of near-surface vertical mixing on scalar quantities, and one that is independent of micrometeorological or climatological observations.

It has been demonstrated that near-surface two-point vertical radon concentration gradients constitute an unambiguous measure of vertical mixing and atmospheric stability (Williams et al., 2013; Chambers et al., 2011; Porstendörfer et al., 1991; Gogolak and Beck, 1980; Malakhov et al., 1966; Jacobi and Andre, 1963). The act of vertical differencing efficiently removes most contributions to the observed radon signal that are related to processes on timescales greater than the diurnal cycle, including synoptic to seasonal variations in fetch regions and tropospheric exchanges with the boundary layer. To date, however, most investigators employing radon as a proxy for atmospheric stability have had access to observations at only a single height (e.g. Wang et al., 2013; Zhang et al., 2012; Perrino et al., 2001, 2008; Sesana et al., 2003; Duenas et al., 1996). If only a single height is available, the unwanted effects of these larger-scale processes need to be eliminated by careful conditioning of the radon time series.

The aims of this study are: (i) to demonstrate that radon observations at a single height can only be used quantitatively as an atmospheric stability indicator if contributions on timescales greater than the diurnal are first removed or reduced by careful conditioning of the time series; (ii) to propose a simple, approximate method for separating these components in a time series of radon observations made from a single height that is well below the minimum depth of a typical stable nocturnal boundary layer ( $\leq 20 \mathrm{~m}$ above ground level, a.g.l.); (iii) outline a simple method for generating a radon-based stability classification scheme on a "whole night" basis; (iv) demonstrate the effectiveness of this scheme by quantifying the influence of increasing atmospheric stability on diurnal concentrations of selected climatological parameters and urban pollutants, and nocturnal mixing depths; and (v) compare the performance of the radon-based scheme against a more traditional (Pasquill-Gifford) categorical stability classification scheme using standard meteorological parameters as input.

\section{Site and observations}

All observations for this study were made on the grounds of the University of Western Sydney, Richmond Campus $\left(33.618^{\circ} \mathrm{S}, 150.748^{\circ} \mathrm{E}\right)$. Richmond is approximately $55 \mathrm{~km}$ inland from the New South Wales coast, $51 \mathrm{~km}$ northwest of the Sydney CBD, and approximately $24 \mathrm{~m}$ a.s.1. While the topography in the immediate vicinity of the site is relatively flat, it is near the western extent of the Sydney Basin, such that the foothills of the Great Dividing Range lie about $5 \mathrm{~km}$ to the west. Unless otherwise specified, results are derived from the 5-year period 2007-2011, all times are local Eastern Standard Time $(\mathrm{EST}=\mathrm{UTC}+10 \mathrm{~h})$, and the southern hemisphere seasonal definition is employed. 
Continuous, direct, hourly atmospheric radon concentration measurements were made using a $1500 \mathrm{~L}$ dual flow loop, two-filter radon detector (e.g. Whittlestone and Zahorowski, 1998; Chambers et al., 2014). Raw counts and detector operational parameters were logged at half-hourly intervals to a CR800 logger (Campbell Scientific, Inc.) and integrated to hourly values for post processing. Air was sampled from a height of $2 \mathrm{~m}$ a.g.l. through $50 \mathrm{~mm}$ I.D. PVC pipe at a flow rate of $\sim 50 \mathrm{~L} \mathrm{~min}^{-1}$. A $400 \mathrm{~L}$ delay volume was incorporated in the intake line to ensure that thoron ( $\mathrm{Rn}-220)$ concentrations entering the detector were less than $0.5 \%$ of their ambient values. The detector had a response time (time to half-peak magnitude) of $45 \mathrm{~min}$, and a lower limit of determination (defined here as the equivalent radon concentration for a detector counting error of $30 \%$ ) of $30 \mathrm{mBq} \mathrm{m}^{-3}$. The detector's instrumental background increases approximately linearly with time, primarily as a function of the accumulation of the long-lived particulate radon daughter $\mathrm{Pb}$ 210 on the second filter. Background checks were performed every three months and the linear $\left(R^{2}=0.99\right)$ background model removed from the raw hourly counts before calibrating to final concentrations. Detector calibrations were also performed every 3 months, by injecting radon for $5 \mathrm{~h}$ from a flow-through Pylon $245 \mathrm{kBq} \pm 4 \% \mathrm{Ra}-226$ source (traceable to NIST standards) at a rate of $80 \mathrm{cc} \mathrm{min}^{-1}$. The coefficient of variability of calibration coefficients over the study period was $5.2 \%$. The combined error on an hourly concentration estimate of $100 \mathrm{mBq} \mathrm{m}^{-3}$ is expected to be $17 \%$. This measurement uncertainty reduces with longer averaging times as $\sim N^{-1 / 2}$ for $N$ hourly samples. Furthermore, the contribution to this uncertainty by the detector's counting error decreases with increasing radon concentration (e.g. from $30 \%$ at $0.03 \mathrm{~Bq} \mathrm{~m}^{-3}$ to $3.5 \%$ at $1 \mathrm{~Bq} \mathrm{~m}^{-3}$ ).

Hourly observations of climatological parameters (wind speed, direction, air temperature and humidity), as well as standard air quality parameters $\left(\mathrm{NO}, \mathrm{NO}_{2}\right.$, Ozone, $\mathrm{SO}_{2}$, $\mathrm{PM}_{2.5}$ ), were provided by the New South Wales Office of Environment and Heritage from a site adjacent to the radon observations. Wind speed and direction were recorded at $10 \mathrm{~m}$ a.g.l., other climate sensors and the intake for air quality observations was situated at $\sim 5 \mathrm{ma}$ a.g.l., on the roof of a small enclosure.

It should be noted that slight calibration problems were evident with the externally provided $\mathrm{NO}$ and $\mathrm{SO}_{2}$ concentrations. An approximately linear drift in the NO data of $0.54 \mathrm{ppb}$ per year was identified and removed, but some uncertainty remains in the absolute values. A slight negative drift in the $\mathrm{SO}_{2}$ calibration was also evident, but the coarse resolution of the data at low concentrations made it difficult to correct. Consequently, small negative $\mathrm{SO}_{2}$ values are occasionally reported for periods of low concentration. However, since the relative changes in concentration are the focus of this study, these issues with the absolute calibrations will be overlooked.

\section{Development of a radon-based stability index}

The observed variability of long-term atmospheric radon measurements represents the superposition of influences acting on a range of scales, including: synoptic to seasonal changes in air mass fetch; synoptic-scale tropospheric exchanges with the boundary layer (via fronts and deep convection); geographically generated mesoscale circulations; and diurnal vertical mixing within the boundary layer. Assuming that local diurnal contributions to the observed radon signal can be meaningfully disentangled from the largerscale ("non-local") contributions, and neglecting the decay of radon over a single night, the nocturnal accumulation of radon near the surface should be primarily controlled by two factors: (a) the mean radon flux from a representative local fetch region, and (b) the strength and extent of vertical mixing, which is closely related to stability and the depth of the nocturnal boundary layer.

\subsection{The seasonal cycle of radon at Richmond}

The composite seasonal cycle of radon at Richmond (Fig. 1a) is characterised by low concentrations November through February and higher concentrations March through October (see also Crawford et al., 2013). Ignoring May for a moment, at least $\sim 30 \%$ of the $4.2 \mathrm{~Bq} \mathrm{~m}^{-3}$ amplitude of mean monthly radon concentrations seen in Fig. 1a is attributable to "nonlocal" effects. This can be seen by inspection of the mean afternoon $(\sim 15: 00 \mathrm{EST})$ radon concentrations in the composite diurnal cycles presented in Fig. 1c (see also Fig. 4a), which exhibit a seasonal range of about $1.5 \mathrm{~Bq} \mathrm{~m}^{-3}$. Afternoon radon values near the surface tend to be representative of the mean concentration through the depth of the daytime convective boundary layer (CBL), which is typically $1 \mathrm{~km}$ or more and changes only slowly from day to day in response to the passage of synoptic scale weather systems. Seasonal migration of the subtropical ridge leads to variations in the recent terrestrial source regions for radon, and frontal systems, deep convection and variations in the depth of the capping inversion affects the degree of dilution of radon within the CBL.

Climatological summaries of the Sydney Basin region (e.g. Crawford et al., 2013; Chambers et al., 2011) show that regional flow for this region in summer is predominantly easterly to southerly, with recent land fetch typically less than half a day. In winter, however, regional flow is often south westerly to westerly, with recent terrestrial fetch over south eastern Australia of the order of 2-3 days. In May, low mean wind speeds often result in longer air mass timeover-land, leading to particularly large nocturnal radon levels (Fig. 1a, b).

The remaining $\sim 70 \%$ of the seasonal variation observed in mean surface radon concentrations at Richmond is attributable to local diurnal effects. The composite diurnal cycle of radon at Richmond (Fig. 1c) is characterised by peak 

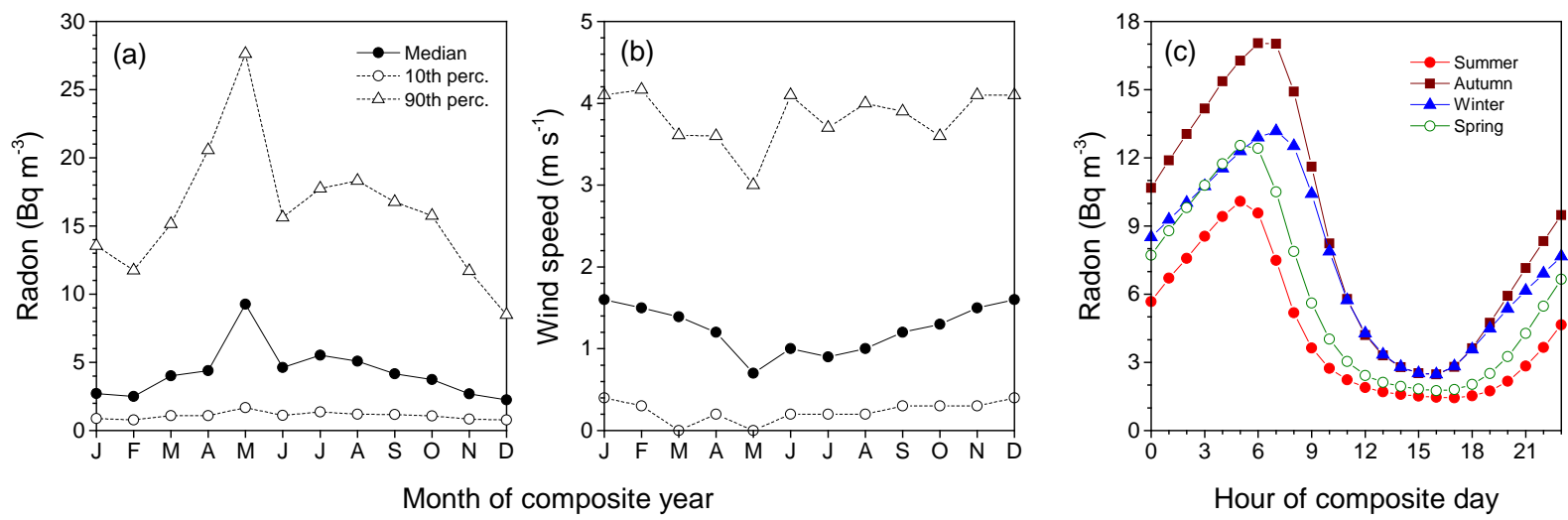

Figure 1. (a, b) Monthly distributions (10th, 50th and 90th percentiles) of radon and wind speed, (c) hourly mean diurnal composite radon by season, at Richmond.

concentrations near sunrise, when the nocturnal boundary layer is at its shallowest, wind speeds tend to be at their lowest and the influence of local sources dominate. Minimum values are found in the mid-afternoon, when the convective boundary layer is at its deepest (maximum dilution), and radon source influences are dominated by the air mass fetch history of the last $\sim 2$ weeks (see discussion above). The timing of the diurnal cycle (Fig. 1c) changes according to seasonal variations in the intensity and duration of incident radiation, with morning peak concentrations shifting from 05:00 EST in summer to 07:00 EST in winter, and the duration of the afternoon minimum period contracting from $6 \mathrm{~h}$ in summer to $2 \mathrm{~h}$ in winter. Typically lower mean wind speeds (Fig. 1b) and colder drier conditions in autumn and winter generate weaker mixing, leading to shallower nocturnal inversions with high radon levels.

\subsection{Isolating the stability-related signal}

Atmospheric stability indices are designed to provide measures of the atmosphere's capacity to support vertical mixing by local turbulence processes. Variations in the observed radon signal due to the "non-local" processes described above, however, are not directly related to atmospheric stability and can be comparable in magnitude to the stabilityrelated variations. The "non-local" radon signal is largest for sites situated near the coast, due to the strong land/ocean contrast in the radon source function, but will be evident to some degree at all sites since the 3.8 day half-life of radon means that fetch regions over the last two weeks or more influence the observed signal. It is therefore important to characterise and remove (or neutralise) the effects of these "non-local" variations prior to application of radon as a quantitative indicator of atmospheric stability.

When vertically resolved radon measurements are available from towers, a two-point radon gradient can be calculated between the lowest and highest intake levels for the purpose of characterising bulk mixing characteristics in the nocturnal boundary layer (Chambers et al., 2011; Williams et al., 2013). This vertical differencing effectively removes contributions to the absolute radon signal on timescales greater than the diurnal. To demonstrate this point, 10 days of radon gradients between 2 and $50 \mathrm{~m}$ from another site within the Sydney Basin (Lucas Heights, $50 \mathrm{~km}$ SSE of Richmond) are presented in Fig. 2. Described in Chambers et al. (2011) and Williams et al. (2013), this site is located on a broad ridge $18 \mathrm{~km}$ from the coast. Topography in the immediate vicinity is moderately complex, with changes in elevation of $\sim 150 \mathrm{~m}$ within a $1 \mathrm{~km}$ radius. 4-day back trajectories (Fig. 3) using the HYSPLIT model (Draxler and Hess, 1998) indicated that the increase in daily minimum (afternoon) radon concentrations from day 253 to day 255 in Fig. 2a was a result of an increasing land fetch over eastern Australia. On day 257, both detectors indicated an abrupt reduction in radon concentration corresponding to a synoptic change in air mass fetch from terrestrial (south westerly) to oceanic (south easterly). Inspection of the corresponding radon gradient time series (Fig. 2b), however, shows no significant influence from either the slow or the abrupt fetch changes. Instead, the maximum radon gradient values attained each night are primarily a measure of the amount of locally sourced radon trapped within the nocturnal inversion. Assuming a local radon source function that is approximately constant in time and space, the gradient time series is thus predominantly a function of stability.

Unfortunately, few sites are set up to conduct vertical radon gradient observations. However, the particular qualities of radon, together with an understanding of its distribution in the boundary layer, allow us below to construct an approximate vertical radon gradient using only measurements at a single height near the surface, for use as a stability indictor.

In the mid-afternoon (Fig. 1c), the ABL is relatively well-mixed from the surface to the synoptic inversion and radon measurements close to the surface are representative of 


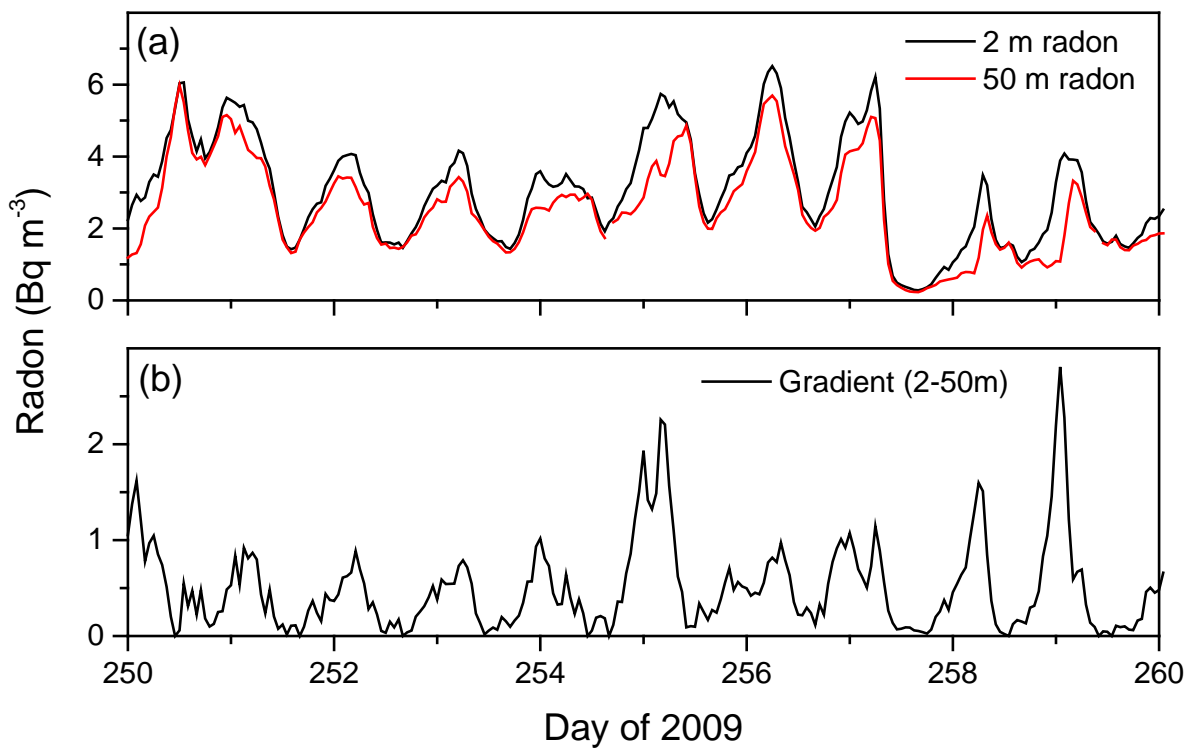

Figure 2. (a) 2 and $50 \mathrm{~m}$ a.g.l. hourly radon concentrations at Lucas Heights, $30 \mathrm{~km}$ southwest of Sydney, in September 2009, and (b) the corresponding hourly radon gradient.

bulk ABL radon concentrations (e.g. Chambers et al., 2011; Williams et al., 2011; Moses et al., 1960). When the ABL is deep and well-mixed, radon concentrations reflect the collective influence of all sources (decay weighted) over the air mass's recent ( $\sim 2$-week) fetch history. After sunset, however, in the absence of low cloud or high winds, an inversion layer begins to form from the ground up as a result of the growing thermal stratification (the stable nocturnal boundary layer, SNBL) (e.g. Collaud Coen et al., 2014; Sesana et al., 2006; Stull, 1980). The radon concentration in the residual layer (RL), the air residing between the top of the SNBL and the previous day's synoptic inversion, remains similar to that of the previous day's ABL (ignoring radon decay; e.g. Kondo et al., 2014) and can therefore be approximated from the previous afternoon's minimum (well-mixed) radon concentration near the surface. By linearly interpolating minimum radon concentrations from one afternoon to the next, it is therefore possible to produce a radon time series similar to that which might be measured by a radon detector with an intake height within the RL. Below the nocturnal inversion, however, the radon concentration of the SNBL evolves largely independently of the overlying radon concentration. Since wind speeds are typically $<1 \mathrm{~m} \mathrm{~s}^{-1}$ on stable nights, the radon that accumulates between the surface and the capping inversion of the SNBL (e.g. morning peak of Fig. 1c) is derived primarily from local sources (i.e. within less than a $40 \mathrm{~km}$ radius; Chambers et al., 2011). A radon "pseudogradient" can thus be formed by computing the difference between the near-surface observations and the constructed time series approximating the radon concentrations in the RL. This pseudo-gradient will be substantially free from variability associated with "non-local" processes and thus mainly in-

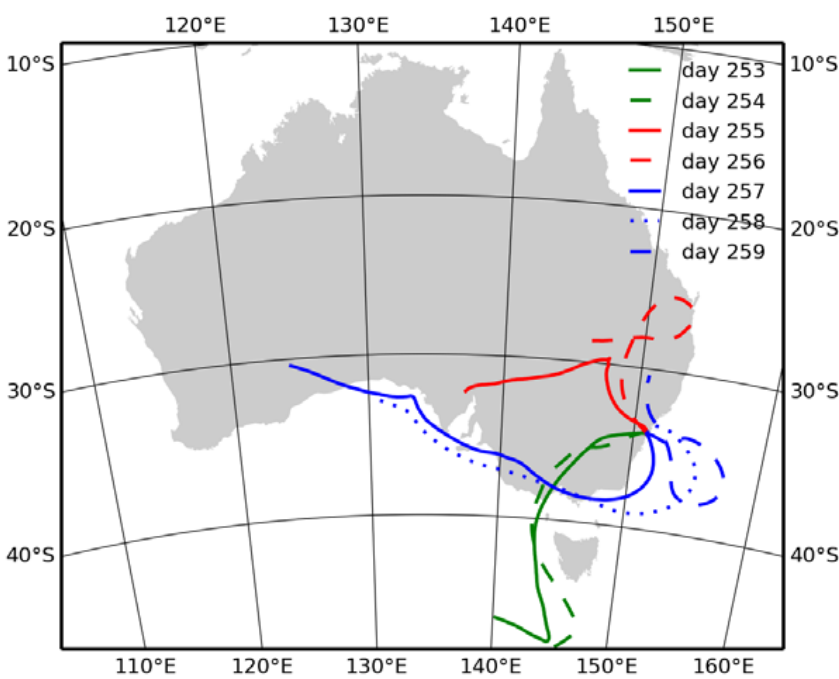

Figure 3. One week of 4-day HYSPLIT back-trajectories depicting conditions of high (red), moderate (green) and low (blue) terrestrial influence on air masses arriving at Lucas Heights, NSW. Each trajectory is the average of five hourly trajectories between 13:00 17:00 LST each day.

fluenced by the strength of the local radon source function (approximately constant) and atmospheric stability.

\subsection{Features of the radon pseudo-gradient}

As an example of the above technique, a 5-week subsection of the 5-year Richmond radon time series is presented in Fig. 4a. Periods of oceanic fetch are evident where daily minimum concentrations drop below $0.5 \mathrm{~Bq} \mathrm{~m}^{-3}$, as well as peri- 


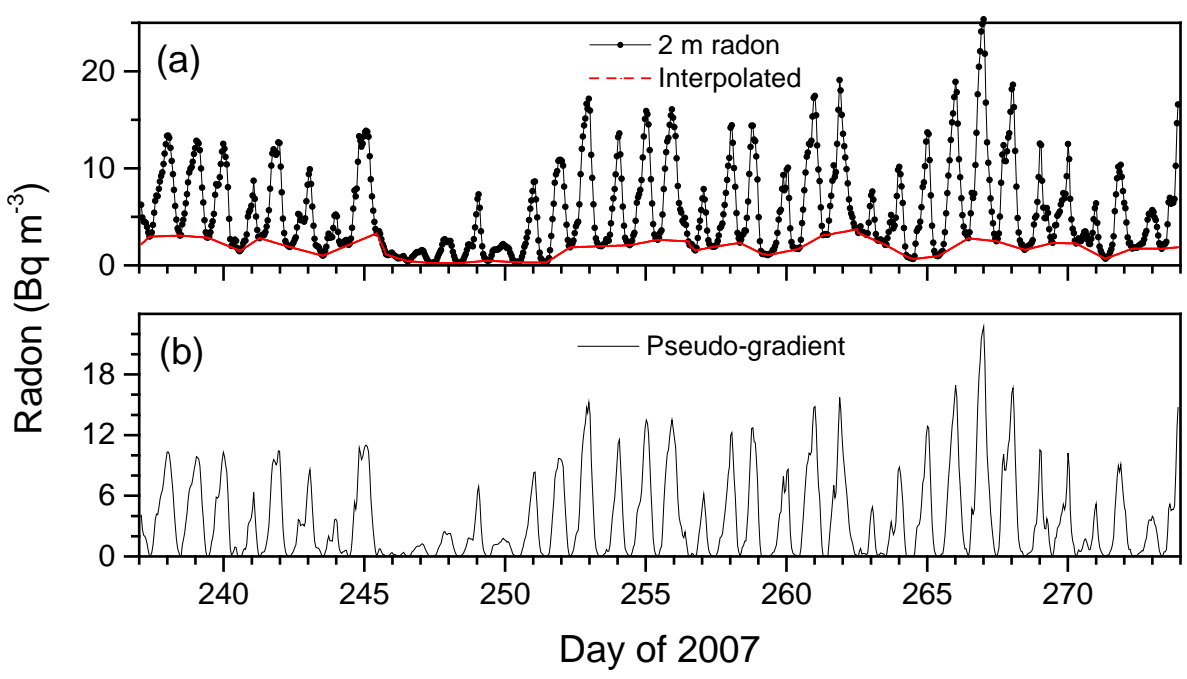

Figure 4. (a) Hourly radon observations at Richmond in September 2007, and afternoon interpolated values, and (b) the Richmond radon gradient (difference between observed and interpolated radon concentrations).

ods of multi-day terrestrial fetch with daily minimum radon concentrations of $3-4 \mathrm{~Bq} \mathrm{~m}^{-3}$. Included in this figure is a linear interpolation between afternoon minimum radon concentrations (red line). The routine used to generate this line identified the minimum hourly radon concentrations between 12:00-18:00 EST each day and linearly interpolated between them. On occasion, when there was a large change in fetch (terrestrial to oceanic) or a large nocturnal mixing event, the difference between the observed radon and the interpolated values (the "pseudo-gradient") sometimes went negative. On such occasions, the routine adjusted the interpolated series by adding additional linear segments (as few as possible) to maintain a non-negative "gradient". A subsection of the resultant pseudo-gradient time series is shown in Fig. 4b.

A feeling for the relative contributions of the "non-local" and stability-driven contributions to the seasonal cycle of radon at Richmond can be obtained by separately considering their monthly mean values (Fig. 5a). There is a pronounced seasonality in both components. In the case of the "non-local" signal, this is mainly due to changes in air mass fetch, as already discussed. Stability-driven contributions are smallest in November through February, when wind speeds are higher (Fig. 1b) and air masses tend to be more humid (fetch predominantly oceanic) so that nocturnal cloud cover is more common. These factors reduce the strength of the nocturnal thermal stratification near the surface, leading to deeper nocturnal boundary layers and lower near-surface radon concentrations. In March through October, the predominantly terrestrial fetch results in drier conditions and more cloud-free nights. This enables strong thermal inversions to form near the surface when wind speeds drop, resulting in near-surface radon concentrations that sometimes exceed $40 \mathrm{~Bq} \mathrm{~m}^{-3}$. May exhibits the largest monthly mean pseudo-gradient, corresponding to the smallest wind speeds (Fig. 1b).

\subsection{Whole-night radon-based stability classification}

A mean hourly diurnal composite plot of the radon gradient is presented in Fig. 5b, with the time axis chosen to emphasise the nocturnal radon build-up, which begins around sunset (18:00) and starts to erode after sunrise (06:00). We define a $12 \mathrm{~h}$ "nocturnal stability window" from 20:00-08:00 (Fig. 5b), chosen to capture the full range of radon concentrations on the majority of nights. The mean radon pseudogradient within the nocturnal stability window was calculated for each night, and then quartile ranges of the cumulative frequency histogram of this quantity (Fig. 6) were used to define the following four radon-based whole-night stability classes:

\begin{tabular}{llll} 
Quartile & $\begin{array}{l}\text { Nocturnal mean } \\
\text { radon gradient }\end{array}$ & $\begin{array}{l}\text { Stability } \\
\text { category }\end{array}$ & $\begin{array}{l}\text { Vertical } \\
\text { mixing }\end{array}$ \\
\hline Q1 & $<2.5 \mathrm{~Bq} \mathrm{~m}^{-3}$ & Near neutral & Strong \\
Q2 & $2.5-6.3 \mathrm{~Bq} \mathrm{~m}^{-3}$ & Weakly stable & Moderate \\
Q3 & $6.3-11.2 \mathrm{~Bq} \mathrm{~m}^{-3}$ & $\begin{array}{l}\text { Moderately stable } \\
\text { Weak }\end{array}$ & $\begin{array}{l}\text { Very weak } \\
\text { Q4 }\end{array}$ \\
\hline $11.2 \mathrm{~Bq} \mathrm{~m}^{-3}$ & Stable &
\end{tabular}

While the nocturnal mean radon gradients reported above are specific to the Richmond site, updated values for any measurement site can be determined by preparing a cumulative frequency diagram (Fig. 6) for the site in question, and reading the new quartile ranges off the graph.

After sorting each whole night of the 5-year data set according to this stability classification, we calculated corresponding diurnal composite radon gradient plots (Fig. 7). For 

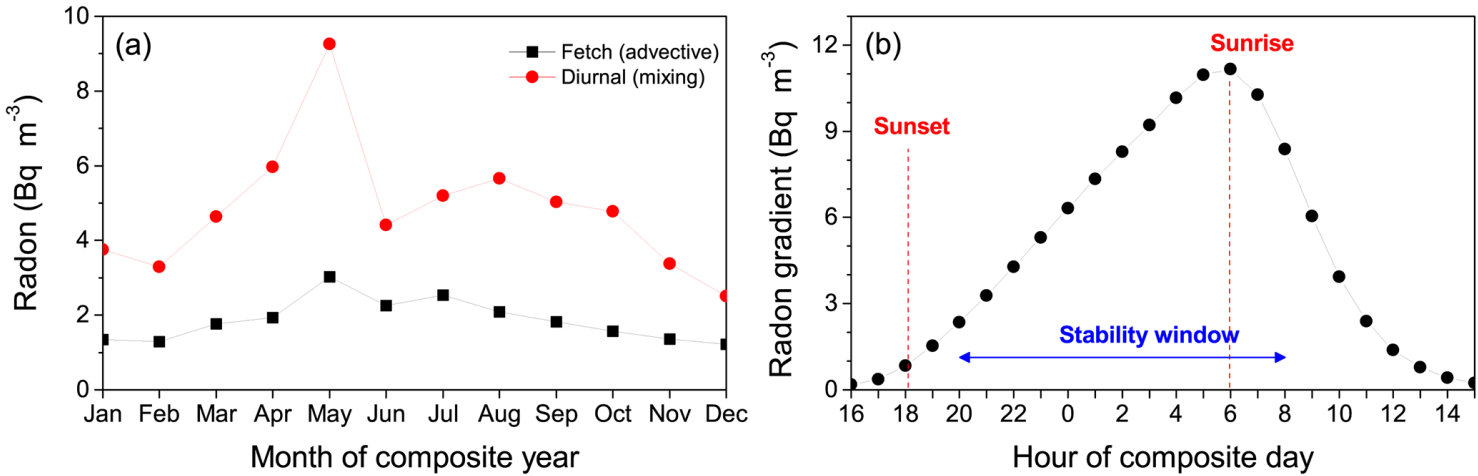

Figure 5. (a) Monthly means of the interpolated ("non-local") and pseudo-gradient (diurnal) radon time series, and (b) diurnal composite plot of the gradient data.

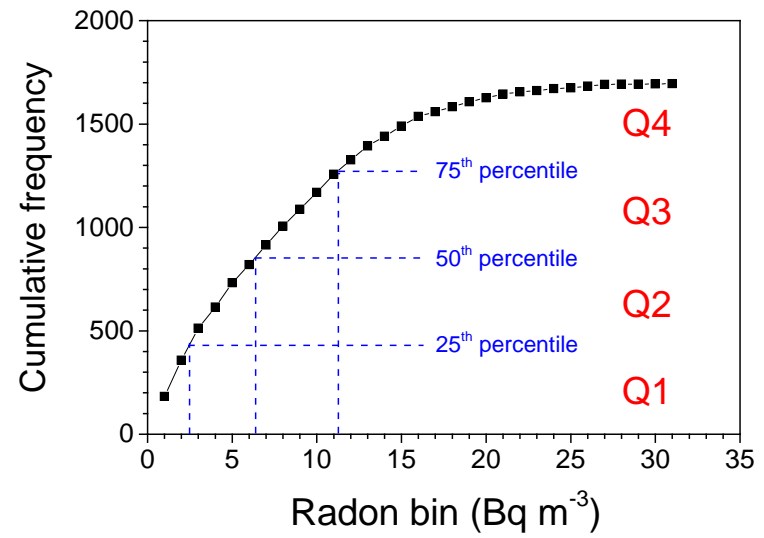

Figure 6. Cumulative frequency histogram of the daily mean pseudo-gradient in the 20:00-08:00 EST window.

nights classified as near-neutral (Q1), there was little nocturnal accumulation of radon and the amplitude of the diurnal cycle was $1.5 \mathrm{~Bq} \mathrm{~m}^{-3}$. By contrast, nights classified as stable $(\mathrm{Q} 4)$ showed a rapid radon build-up after sunset, peaking near sunrise, with a mean diurnal amplitude of $22.9 \mathrm{~Bq} \mathrm{~m}^{-3}$.

\section{Results}

\subsection{Evaluation against meteorological data}

Standard climatological observations were available at Richmond during the period of this study. Of these observations, the parameters most easily relatable to measures of stability and/or mixing are: wind speed, standard deviation of wind direction, and temperature. Diurnal composite plots of these parameters, grouped solely by our radon-based stability classification scheme for whole nights, are shown in Fig. 8.

Nocturnal (20:00-06:00) wind speeds were highest for the nights classified as "near neutral" (on average almost $2 \mathrm{~m} \mathrm{~s}^{-1}$ ). High wind speeds result in a deep, mechanically mixed nocturnal boundary layer, and these periods also ex-

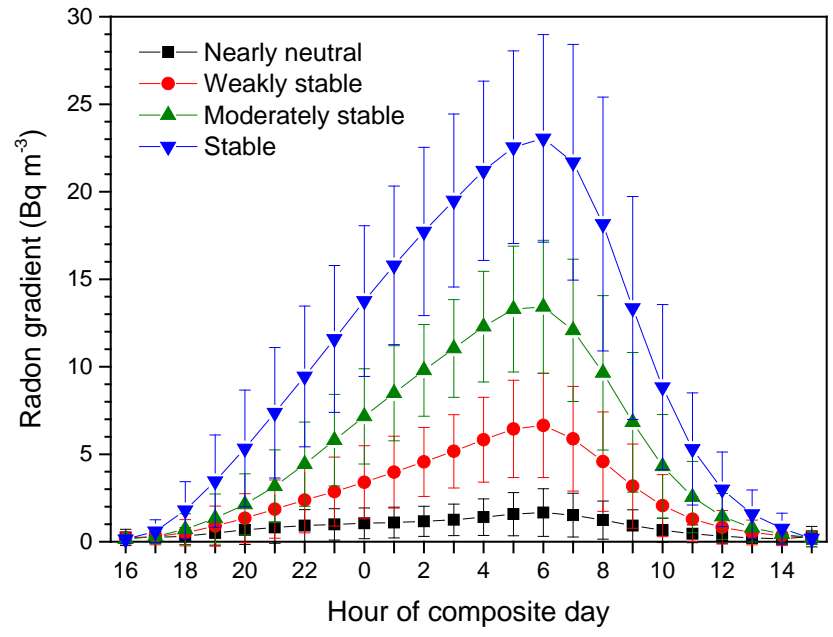

Figure 7. Hourly mean diurnal composite radon gradient plots for the four designated nocturnal stability categories. Each curve represents an average of between 410-420 whole days of observations; whiskers represent $\pm 1 \sigma$.

hibited the smallest diurnal amplitude in wind speed and temperature as well as a comparatively small standard deviation of wind direction. Such characteristics are consistent with overcast conditions and the passage of frontal weather systems. The smallest mean nocturnal wind speeds were observed on nights classified as "stable" by the radon method, usually dropping below $0.5 \mathrm{~m} \mathrm{~s}^{-1}$. However, even the weakly stable evenings had wind speeds $<1 \mathrm{~m} \mathrm{~s}^{-1}$, which is consistent with Sesana et al. (2003) who reported no significant nocturnal accumulation for wind speeds above $1.5 \mathrm{~m} \mathrm{~s}^{-1}$.

The stable nights also exhibited the greatest standard deviation of wind direction, consistent with the presence of meandering mesoscale flows within the shallow SNBL. The amplitude of the diurnal temperature signal in cases identified as stable was greater than for the other categories, as would be expected for predominantly clear-sky conditions. Furthermore, atmospheric pressure (not shown) was $2 \mathrm{hPa}$ greater on 

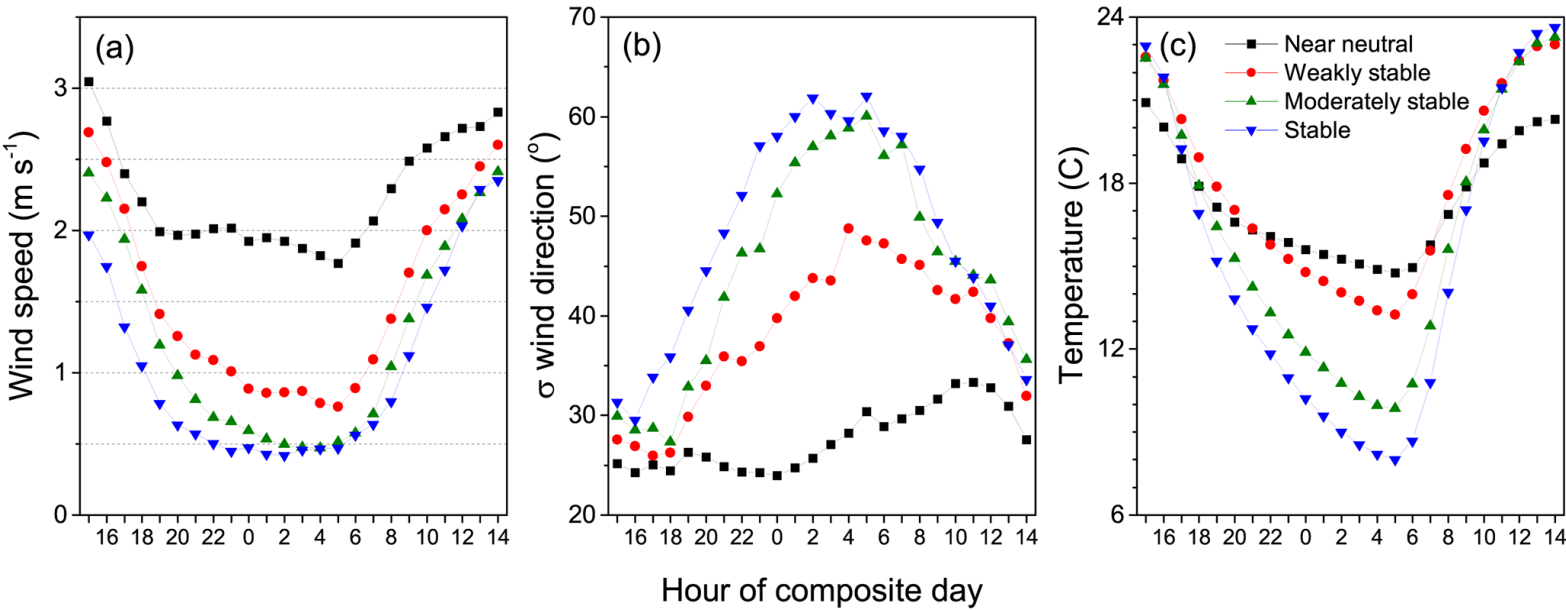

Figure 8. Mean hourly diurnal composite plots of (a) $10 \mathrm{~m}$ wind speed, (b) $10 \mathrm{~m}$ standard deviation of wind direction, and (c) $5 \mathrm{~m}$ air temperature.

average in the "stable" cases, consistent with anti-cyclonic activity and regional subsidence.

\subsection{Evaluation against urban pollution data}

In the previous section, it was seen that the radon-based atmospheric stability classification scheme is clearly an effective quantitative tool for delineation between various nocturnal atmospheric mixing states. As a further evaluation, we used the new classification scheme to quantify changes in various urban pollutant concentrations as a function of atmospheric stability. As can be seen in Fig. 9, despite the "whole night" resolution of the radon-based stability classification scheme, it is capable of characterising the influence of nocturnal mixing on primary and secondary gaseous and aerosol pollutants.

In the case of $\mathrm{NO}, \mathrm{NO}_{2}$ and $\mathrm{PM}_{2.5}$, the most stable atmospheric conditions (shallow mixing depths) identified by this scheme are associated with dramatically increased nearsurface pollutant concentrations. On average, the diurnal range of NO increases from $1.6 \mathrm{ppb}$ under well mixed conditions to $14 \mathrm{ppb}$ under the most stable conditions. The corresponding diurnal range increase for $\mathrm{NO}_{2}$ is 2.8 to $9.4 \mathrm{ppb}$, and for $\mathrm{PM}_{2.5} 3.6$ to $12 \mu \mathrm{g} \mathrm{m}^{-3}$. However, increasing atmospheric stability has the opposite effect on near-surface concentrations of ozone and $\mathrm{SO}_{2}$. Since ozone is highly reactive, when trapped in a shallow inversion layer (stable class) surface deposition processes and titration by NO emitted by vehicles rapidly reduce the concentration. Conversely, when near-surface wind speeds are higher (near-neutral class), ozone is mixed downward from the overlying air mass, resulting in higher nocturnal concentrations. Similarly for $\mathrm{SO}_{2}$, when trapped in a shallow inversion layer chemical sink processes rapidly reduce the near-surface concentration of $\mathrm{SO}_{2}$ formerly present in the ABL. Since there are no significant sources of $\mathrm{SO}_{2}$ in the immediate vicinity of Richmond, no accumulation is observed leading up to sunrise.

As was the case for the climatological variables, the diurnal behaviour of each pollutant species in each of the radonbased stability categories was clearly consistent with current knowledge for urban areas (e.g. $\mathrm{O}_{3}$, Avino et al., 2003; Acker et al., 2006; Di Carlo et al., 2007; Zhang et al., 2012, Pitari et al., 2014; $\mathrm{SO}_{2}$, Jenner et al., 2012; $\mathrm{PM}_{2.5}$, Gupta et al., 2007).

While Fig. 9 clearly demonstrates a close correspondence between mean nocturnal radon accumulation near the surface and pollutant concentrations, the pronounced differences in diurnal cycle characteristics between radon (Fig. 7) and urban pollutants (Fig. 9), largely brought about by spatiotemporal differences in their sources and sinks, can result in low, or highly variable, correlations between radon and specific pollutant concentrations.

\subsection{Comparison with Pasquill-Gifford stability classification}

Pasquill-Gifford (P-G) atmospheric stability typing (Pasquill, 1961; Turner, 1964; Pasquill and Smith, 1983) is usually employed to facilitate estimates of lateral and vertical dispersion parameters in Gaussian plume models. The $\mathrm{P}-\mathrm{G}$ stability categories employed here were defined according to the turbulence-based variation of Turner's method (Turner, 1964), based on scalar mean wind speed and the standard deviation of wind direction. In all, there are seven $\mathrm{P}-\mathrm{G}$ stability categories ranging from $\mathrm{A}$ through $\mathrm{G}$ (Table 1), although for many regulatory applications (and the turbulence-based version of Turner's method) the more strongly stable categories $\mathrm{F}$ and $\mathrm{G}$ are grouped together. The key used for assigning the $\mathrm{P}-\mathrm{G}$ turbulence stability categories are provided in Tables 2 and 3 (see also USEPA, 2007). 

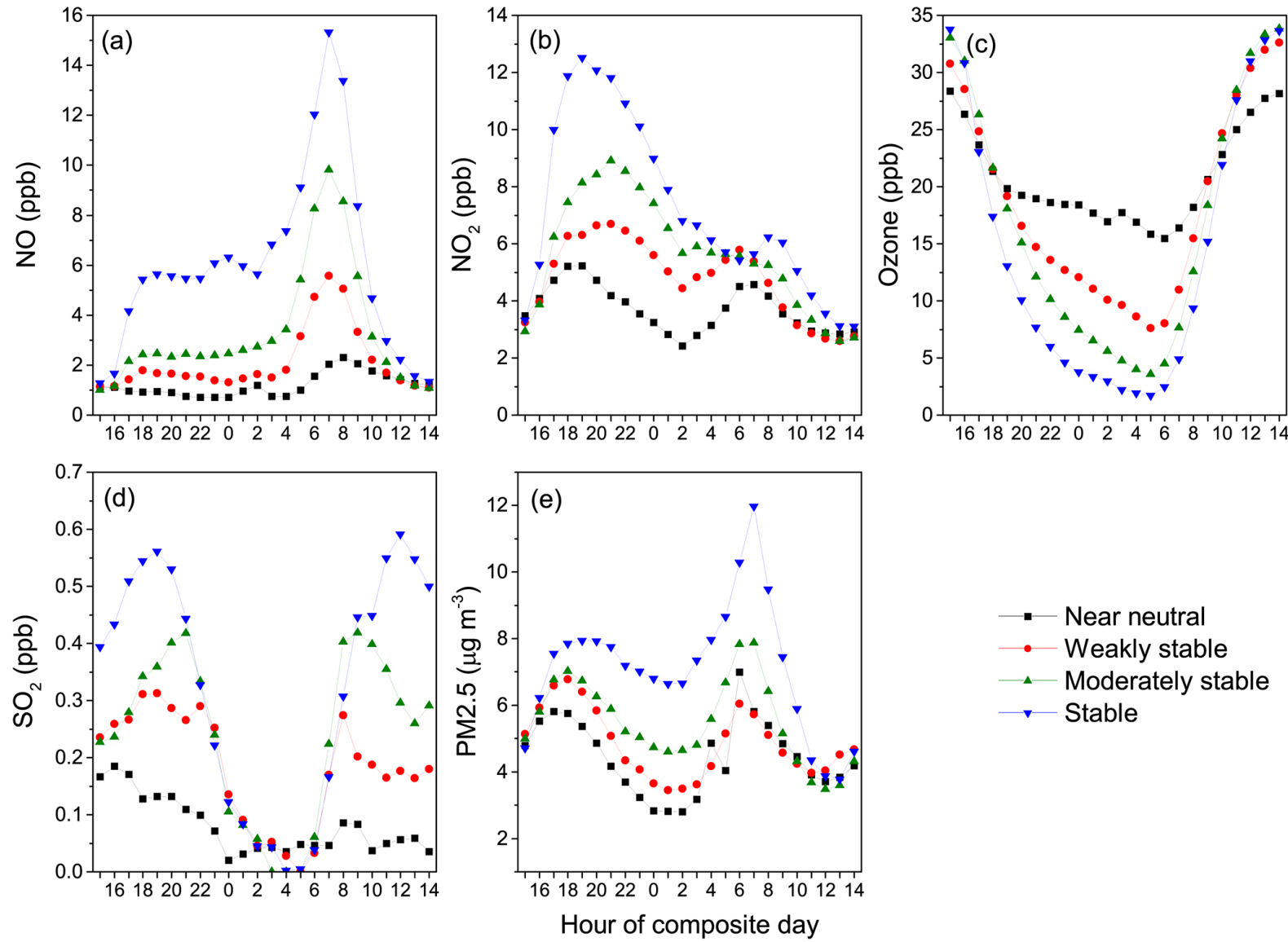

Figure 9. Mean hourly diurnal composites of (a) $\mathrm{NO}$, (b) $\mathrm{NO}_{2}$, (c) Ozone, (d) $\mathrm{SO}_{2}$, and (e) $\mathrm{PM}_{2.5}$, for each of the four radon-derived atmospheric stability classifications.

Table 1. Pasquill-Gifford stability class names.

\begin{tabular}{ll}
\hline Class & Description \\
\hline A & Extremely unstable \\
B & Moderately unstable \\
C & Weakly unstable \\
D & Neutral \\
E & Weakly stable \\
F & Moderately stable \\
G & Strongly stable
\end{tabular}

All hourly data of the 5-year data set was assigned a $\mathrm{P}$ $\mathrm{G}$ turbulence stability category according to Tables 2 and 3 . To best match the classification performed by the radonbased technique, we then assigned "whole-night" P-G stability classes based on the modal (most common) hourly stability category defined over the 9-hour period 21:00-05:00 EST; a reduced nocturnal window compared to the radon method was used here to avoid the lag known to exist between hourly P-G stability categories and radon-separate concentrations (Duenas et al., 1996). Lastly, we categorised the climatologi-
Table 2. Lateral turbulence criteria; step 1 of $\mathrm{P}-\mathrm{G}$ turbulence stability classification.

\begin{tabular}{lr}
\hline $\begin{array}{l}\text { Initial estimate of } \\
\text { P-G category }\end{array}$ & $\begin{array}{r}\text { Standard deviation of } \\
\text { wind direction } \sigma \theta\left(^{\circ}\right)\end{array}$ \\
\hline A & $22.5 \leq \sigma \theta$ \\
B & $17.5 \leq \sigma \theta<22.5$ \\
C & $12.5 \leq \sigma \theta<17.5$ \\
D & $7.5 \leq \sigma \theta<12.5$ \\
E & $3.8 \leq \sigma \theta<7.5$ \\
F & $\sigma \theta<3.8$ \\
\hline
\end{tabular}

cal and pollutant concentration data on a whole-day basis according to the assigned $\mathrm{P}-\mathrm{G}$ stability class; selected results are shown in Fig. 10.

Using the radon "gradient" data as a benchmark (Fig. 10a cf. Fig. 7), the P-G stability classes D-F appear to fall roughly between the four radon-defined stability classes. For example, peak radon concentrations for the moderately and strongly stable classifications in the radon-based scheme were 13 and $23 \mathrm{~Bq} \mathrm{~m}^{-3}$, respectively, whereas the peak "very 

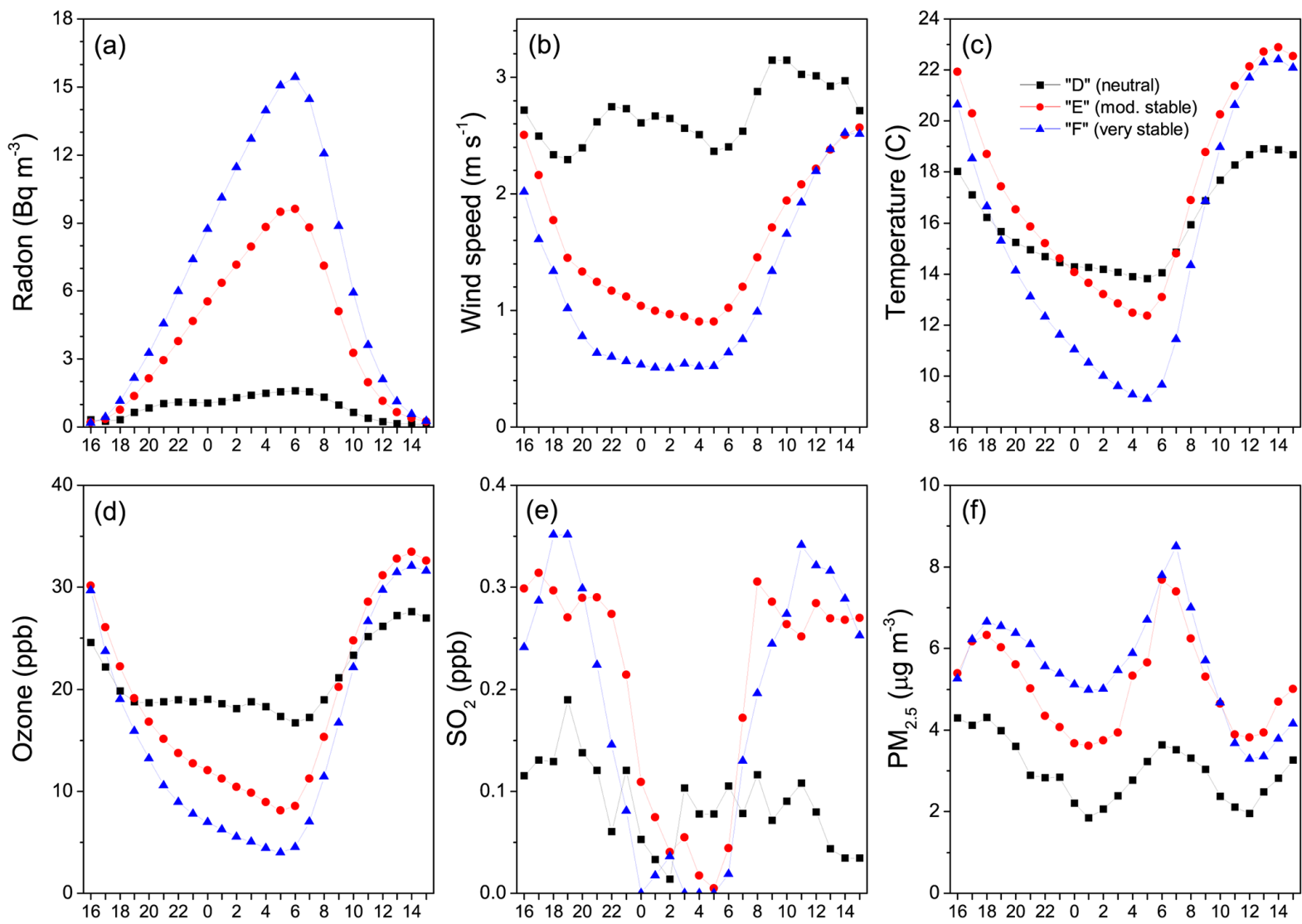

Hour of composite day

Figure 10. Mean hourly diurnal composite plots of selected climatological and pollution quantities for whole days categorised by their dominant nocturnal Pasquill-Gifford stability category: D - neutral; E - weakly stable; F - moderately stable.

stable" $\mathrm{P}-\mathrm{G}$ turbulence value was $16 \mathrm{~Bq} \mathrm{~m}^{-3}$. This indicates that the $\mathrm{P}-\mathrm{G}$ "very stable" category is less selective of the strongly stable nights than the equivalent category in the radon-based scheme, a fact that is confirmed by a smaller amplitude in the diurnal temperature composite in Fig. 10c (cf. Fig. 8c). Comparing the morning evolution of near-surface temperature between days classified as stable by the two schemes, fewer of the days classified as stable by the P$\mathrm{G}$ turbulence scheme appear to develop into clear-sky convective conditions than is the case for the radon scheme. In fact, mornings of $\mathrm{P}-\mathrm{G}$ "stable" days are cooler than the $\mathrm{P}-$ G "moderately stable" days. Both schemes predict nocturnal wind speeds of around $0.5 \mathrm{~m} \mathrm{~s}^{-1}$ under the most stable conditions, whereas the $\mathrm{P}-\mathrm{G}$ scheme attributes a smaller proportion of wind speed events to the neutral category, as evident from the higher mean wind speed and greater variability over the diurnal cycle.

Perhaps most significantly, the fact that the $\mathrm{P}-\mathrm{G}$ "stable" category is less selective of the strongly stable nights than the radon-based scheme means that the relationship between atmospheric stability and peak nocturnal pollutant concentrations are underestimated by the P-G scheme (Fig. 10e cf.
Fig. 9d for $\mathrm{SO}_{2}$; Fig. 10f, cf. Fig. 9e for $\mathrm{PM}_{2.5}$ ). Such discrepancies $(30-50 \%)$ can have significant implications for public exposure records and would influence air quality management.

\section{Discussion}

\subsection{Applicability, limitations and caveats}

While the method described here to derive the radon-based stability classification scheme is applicable to most nearsurface radon (or radon progeny) time series, the absolute threshold values adopted for the four stability classifications (shown in Fig. 6) will vary according to site-specific changes in the frequency distribution of the nocturnal mean radon gradient (see Sect. 3.4). At sites that experience consistent snow cover or freezing soils, separate stability classifications may needed for the "warm" and "cold" parts of the year to account for changes to the local radon source function. Similarly, at sites where there is a large summer/winter change in daylight hours, separate seasonal stability classification 
Table 3. Wind speed adjustments to determine final estimate of $\mathrm{P}-\mathrm{G}$ turbulence categories.

\begin{tabular}{|c|c|c|c|}
\hline Time of day & $\begin{array}{l}\text { Initial estimate of } \\
\text { P-G category }\end{array}$ & $\begin{array}{l}10 \mathrm{~m}_{\text {wind }} \text { speed } \\
\left(\mathrm{m} \mathrm{s}^{-1}\right)\end{array}$ & $\begin{array}{l}\text { Final estimate of } \\
\text { P-G category }\end{array}$ \\
\hline \multirow[t]{10}{*}{ Day } & A & $\mathrm{u}<3$ & A \\
\hline & A & $3 \leq u<4$ & B \\
\hline & A & $4 \leq u<6$ & $\mathrm{C}$ \\
\hline & A & $6 \leq u$ & D \\
\hline & B & $\mathrm{u}<4$ & B \\
\hline & B & $4 \leq u<6$ & $\mathrm{C}$ \\
\hline & B & $6 \leq u$ & D \\
\hline & $\mathrm{C}$ & $\mathrm{u}<6$ & $\mathrm{C}$ \\
\hline & $\mathrm{C}$ & $6 \leq u$ & D \\
\hline & $\mathrm{D}, \mathrm{E}$ or $\mathrm{F}$ & ANY & D \\
\hline \multirow[t]{14}{*}{ Night } & A & $\mathrm{u}<2.9$ & $\mathrm{~F}$ \\
\hline & A & $2.9 \leq u<3.6$ & E \\
\hline & A & $3.6 \leq u$ & D \\
\hline & B & $\mathrm{u}<4$ & F \\
\hline & B & $4 \leq u<6$ & E \\
\hline & B & $6 \leq u$ & D \\
\hline & $\mathrm{C}$ & $\mathrm{u}<6$ & E \\
\hline & $\mathrm{C}$ & $6 \leq u$ & D \\
\hline & D & ANY & D \\
\hline & E & $\mathrm{u}<4$ & E \\
\hline & E & $4 \leq u$ & D \\
\hline & $\mathrm{F}$ & $\mathrm{u}<4$ & $\mathrm{~F}$ \\
\hline & $\mathrm{F}$ & $4 \leq u<6$ & $\mathrm{E}$ \\
\hline & $\mathrm{F}$ & $6 \leq u$ & D \\
\hline
\end{tabular}

may be required to account for differences in nocturnal accumulation times. Furthermore, for sites located at, or close to (say $<20 \mathrm{~km}$ ) the coast, it may be necessary to derive varying thresholds for the classification scheme which take into account the fact that part of the nocturnal radon footprint may be over the ocean with effectively zero flux (e.g. onshore vs. offshore flow). It is also important to note that the choice of four stability classes in this study was essentially arbitrary. The number of stability classes used to apportion the nocturnal radon data could be increased if desired, although care needs to taken to ensure that a sufficient number of observations remain within each defined category to provide statistically sound results. Based on the five years of observations used here, results from each of the four stability categories represented in Figs. 8 and 9 were derived from approximately 400 individual observations (for each hour of each curve in the diurnal composites).

Although radon gradients are calculated hourly, stability classifications in this study have been defined on a "wholenight" basis (20:00-08:00). This was done so that a meaningful analysis of "typical" diurnal patterns could be performed. While intermittent events of various natures can seriously disrupt the atmospheric stability regime on a given night, long-term observations in the Sydney Basin reported by Chambers et al. (2011) have indicated that in more than $70 \%$ of cases a night that begins within a broadly defined stability category will usually persist as such. As evident from the daytime values of Figs. 8 and 9, this level of synoptic "persistence" often extends for the whole day; e.g. stable nights are often associated with, warm, clear-sky days. Having said this, there is no strong reason why radon gradients could not be applied on an hourly basis, for example in an operational environment. If "future" values are unavailable, an estimation of the current RL value can be obtained simply by extrapolating the minimum value from the previous afternoon. The uncertainties introduced by this additional approximation have not been estimated in the current study, but are likely to be small in general.

Since it is usually the larger-scale synoptic conditions that drive atmospheric stability conditions at the surface, the stability categories derived from the current approach are often applicable to a broader region than the immediate vicinity of the observations. For example, an atmospheric stability classification scheme based on hourly radon observations from Warrawong (70 km south of the Sydney CBD; Chambers et al., unpublished data), was more successful at categorising hourly measurements of $\mathrm{NO}, \mathrm{NO}_{2}$, Ozone and $\mathrm{PM}_{2.5}$ at a site $10 \mathrm{~km}$ to its north, than a Pasquill-Gifford scheme calculated from climatological observations made adjacent to the pollution monitoring station. A corollary of this observation is that, while multiple pollution monitoring stations might be required to assess the pollutant levels for a large urban region (Duenas et al., 1996), a single radon monitoring station could be sufficient to assess the nightly stability regime of a region within a radius of $10 \mathrm{~s}$ of $\mathrm{km}$, large enough to cover a modestly sized urban area. Furthermore, it is important to note that the method of stability classification outlined here is completely independent of any climatological or micro-meteorological observations, making it a simple and economical alternative to conventional approaches to stability classification.

The consistent and effective way in which the radon-based stability classification scheme resolves the diurnal behaviour of gaseous and fine-particle urban emissions is likely to be a valuable tool in the assessment of chemical transport model performance, by providing diurnal composite pollutant concentrations for a range of nocturnal mixing depths which may, or may not, be resolved by a given model. Since this method enables hourly distributions to be calculated for each quantity over the diurnal cycle for a range of stability classifications, it would be an ideal benchmarking tool.

\subsection{Stability influences on mixing depth: a box model analysis}

An alternative interpretation of radon measurements in the stable boundary layer is possible with time-resolved measurements. Radon is assumed to be emitted with a constant flux, $F$; into a well-mixed box. The height of the box can be determined from the near-surface radon concentration, $C$, if radon emissions are known.

The box-model approach has been used for several studies since the 1970s (including Pitari et al., 2014; Griffiths et al., 2013; Grossi et al., 2012; Di Carlo et al., 2007; Sesana et 
al., 2006; Galmarini, 2006; Pasini and Ameli, 2003; Kataoka, 1998; Allegrini et al., 1994; Fujinami and Esaka, 1988; Guedalia et al., 1980; Fontan et al., 1979). In the model, the change in radon concentration within the well-mixed layer adjacent to the surface is due to a balance between surface emissions, radioactive decay and, if the layer is growing, dilution. These assumptions lead to the budget equation:

$\frac{\mathrm{d} C}{\mathrm{~d} t}=F / h_{\mathrm{e}}-\lambda C-D$,

where $\lambda=2.098 \times 10-6 \mathrm{~s}^{-1}$ is the radon decay constant, $\mathrm{D}$ is the dilution term, nonzero when the boundary layer is growing and therefore entraining low concentration air from above, and here the radon flux, $F$, is assumed to be $20 \mathrm{mBq} \mathrm{m}^{-2} \mathrm{~s}^{-1}$, a representative value for New South Wales (Griffiths et al., 2010).

Equation (1) can be solved iteratively to obtain a timeseries of the effective mixing depth, $h_{\mathrm{e}}$ (Griffiths et al., 2013) or can be solved analytically by assuming that $D=0$. If dilution is assumed to be zero, we call the resultant length-scale the accumulated estimate of the mixing height, $h_{\text {acc }}$, which is given by Fontan et al. (1979) as:

$h_{\mathrm{acc}}=\frac{F\left(1-e^{-\lambda t}\right)}{\lambda\left(C-e^{-\lambda t} C_{0}\right)}$,

where $\mathrm{C}_{0}$ is the concentration at time $t=0$, the time when radon concentration reaches its minimum. The effect of radioactive decay is included in Eq. (2), although over the course of a single night it only changes the estimated mixing length scale by less than $5 \%$.

We used the above two methods to calculate the hourly nocturnal mixing depth since sunset, then - based on the $5 \mathrm{~h}$ before sunrise each morning - calculated the distributions (10th, 50th, and 90th percentiles) of mixing depths for each stability category (Fig. 11).

Based on these mixing height estimates the pseudogradient classification method leads to similar results as either of the box-model approaches $\left(h_{\mathrm{e}}\right.$ or $\left.h_{\mathrm{acc}}\right)$, in spite of the different conceptual framework. Stronger agreement is seen with $h_{\text {acc }}$ than with $h_{\mathrm{e}}$, and this is not surprising since $h_{\text {acc }}$ - like the pseudo-gradient - is based on a measured change since the previous afternoon's minimum.

Under the most stable conditions the radon-based mixing length scale is typically $30-35 \mathrm{~m}$, but occasionally drops below 20-25 m. For the near neutral (well mixed) cases, however, the nocturnal boundary layer is typically $400-500 \mathrm{~m}$ deep, but occasionally over $1000 \mathrm{~m}$.

\subsection{Seasonal and fetch effects on extreme pollution events}

As we have a sufficiently long (5-year) data set at Richmond, it is possible to analyse stability effects on pollutant concentrations as a function of season and air mass fetch. Figure 12 compares winter and summer concentrations of $\mathrm{PM}_{2.5}, \mathrm{SO}_{2}$ and ozone in very stable (extreme pollution) conditions. At Richmond, there are strongly contrasting urban signatures within the air mass fetch for winter and summer. In winter, as previously mentioned, regional flow is mainly from the west to south west; emissions are typically of a rural or domestic nature. In summer, however, air mass fetch varies from east to south; frequently directly from the Sydney CBD (to the southeast).

In winter, the peak $\mathrm{PM}_{2.5}$ concentrations (occasionally exceeding $15 \mu \mathrm{g} \mathrm{m}^{-3}$ ) occur in the morning, when accumulated smoke from domestic heating around Richmond and the foothills dominates. During the days, however, the westerly fetch covers extensive forested regions of the Great Dividing Range, and $\mathrm{PM}_{2.5}$ concentrations are comparatively low. In summer, both the morning and evening traffic plumes are evident in the $\mathrm{PM}_{2.5}$ concentrations, and - despite deeper daytime ABL depths in summer than winter - the daytime $\mathrm{PM}_{2.5}$ concentrations from Sydney are more than double that observed from the west.

Wintertime $\mathrm{SO}_{2}$ concentrations are generally low at Richmond; during the days, when atmospheric mixing is deepest, the slightly elevated $\mathrm{SO}_{2}$ concentrations likely represent advection from distant pollution sources. For example, Cohen et al. (2012) estimated that $30-50 \%$ of sulfate measured in the greater Sydney region during the cooler months of the year was attributable to releases from distant coal-fired power stations. In summer, $\mathrm{SO}_{2}$ concentrations are higher overall, with morning and evening traffic-related peaks evident (although delayed compared to $\mathrm{PM}_{2.5}$ ). Although derived from near-surface sources, this urban $\mathrm{SO}_{2}$ can mix throughout the $\mathrm{ABL}$ en route to Richmond (> $30 \mathrm{~km}$ from Sydney). Since stable nocturnal conditions are usually associated with clearsky days, these represent the peak ozone times for the respective seasons. In summer, when fetch is from the Sydney CBD and solar insolation is much greater, ozone concentrations are seen to occasionally (15-20\% of the time) exceed $60 \mathrm{ppb}$; almost twice the peak concentrations observed in winter.

For comparison with the distributions reported here $(\mu \pm 1 \sigma)$ of the most stable atmospheric conditions for this 5-year period, as presented in Fig. 12) the $\mathrm{Na}$ tional standards for criteria air pollutants in Australia guidelines (http://www.environment.gov.au/resource/ national-standards-criteria-air-pollutants-1-australia) state that: daily mean $\mathrm{PM}_{2.5}$ concentrations should not exceed $25 \mu \mathrm{g} \mathrm{m}^{-3}$, hourly average $\mathrm{SO}_{2}$ concentrations should not exceed $200 \mathrm{ppb}$, and hourly averaged ozone concentrations should not exceed $100 \mathrm{ppb}$.

\section{Summary and conclusions}

We used 5-years (2007-2011) of continuous hourly surface atmospheric radon measurements at Richmond NSW with a $1500 \mathrm{~L}$ two-filter dual flow-loop radon detector, to demon- 

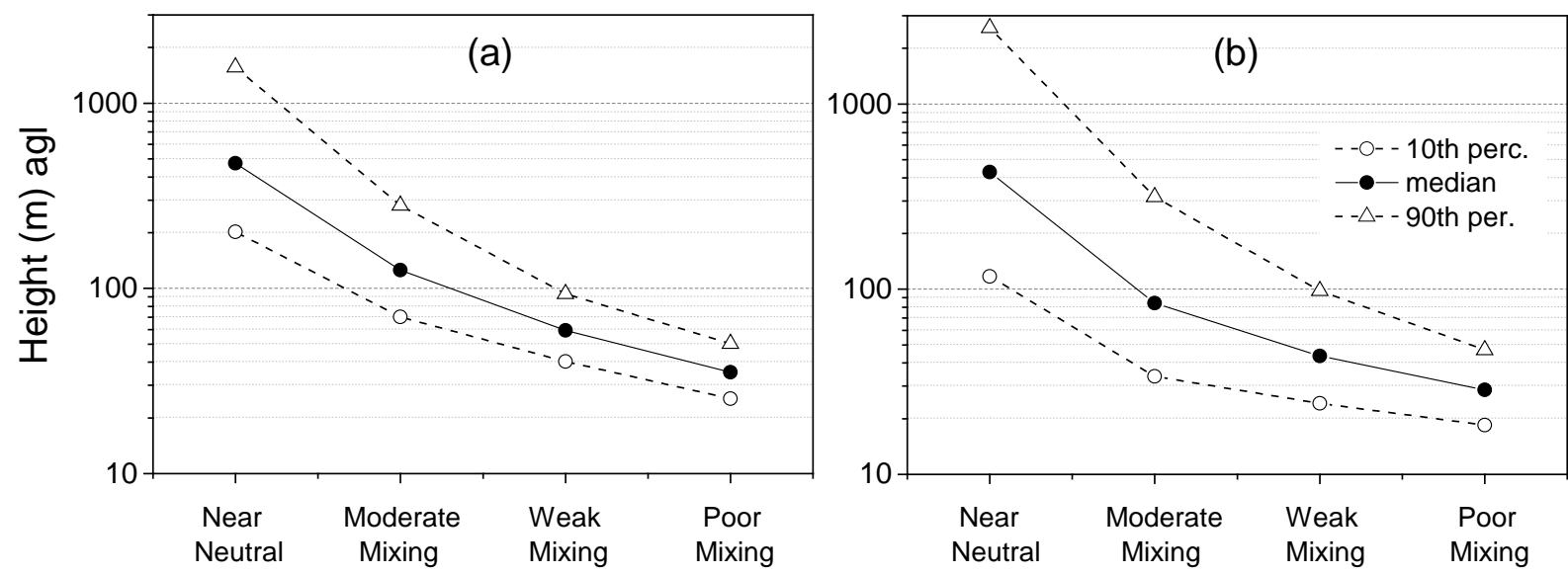

Stability / Mixing category

Figure 11. Distributions of estimated nocturnal mixing depth as a function of radon-derived stability class for (a) accumulated mixing heights $\left(h_{\mathrm{a}}\right)$, and (b) equivalent mixing heights $\left(h_{\mathrm{e}}\right)$.
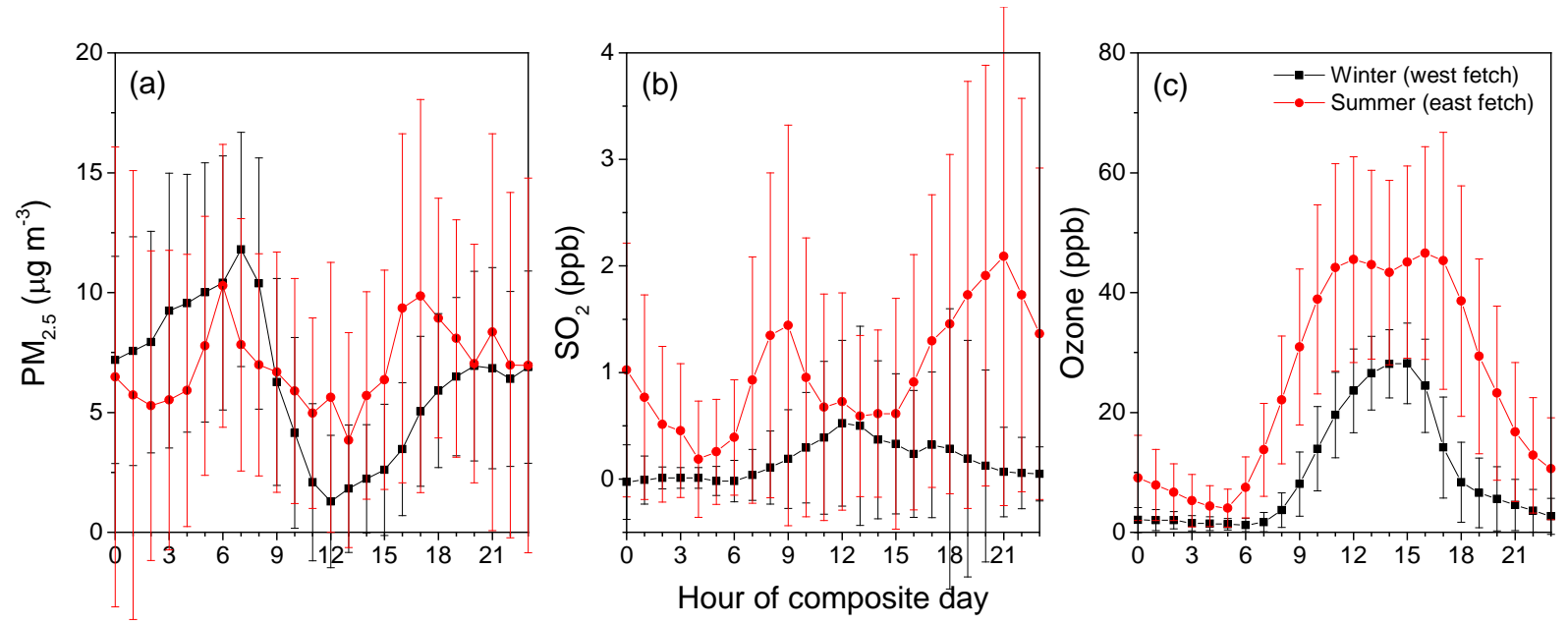

Figure 12. Comparison of hourly mean diurnal composites under "stable" atmospheric conditions in winter and summer for (a) $\mathrm{PM}_{2.5}$, (b) $\mathrm{SO}_{2}$, and (c) $\mathrm{O}_{3}$; whiskers represent $\pm 1 \sigma$. Note difference in time axis cf. Fig. 9.

strate a technique that isolates local diurnal contributions to the radon signal and uses them to derive a four category radon-based scheme for classifying atmospheric stability on a "whole night" basis. Compared to some other stability classification approaches (e.g. Perrino et al., 2001), this method is simple to implement. It is also a robust and economical alternative to radon gradient observations when data from only a single height is available. Without first removing contributions on greater than diurnal timescales, radon data cannot be used quantitatively as an accurate indicator of atmospheric stability.

Using the devised scheme, we classified and subdivided a selection of climatological and pollution observations according to nocturnal stability conditions; results were consistent and well-resolved annually and seasonally. As condi- tions progressed from near-neutral to stable, mean nocturnal wind speeds reduced from 2 to $0.5 \mathrm{~m} \mathrm{~s}^{-1}$, with a corresponding increase in the wind direction standard deviation from 25 to $60^{\circ}$. On average, the diurnal amplitude of $\mathrm{NO}\left(\mathrm{NO}_{2}\right)$ increased from 1.6 (2.8) ppb under near-neutral conditions, to 14 (9.4) ppb under stable conditions; the corresponding increase in $\mathrm{PM}_{2.5}$ diurnal range is 3.3 to $8.19 \mu \mathrm{g} \mathrm{m}^{-3}$.

Comparison of the radon-based scheme against a commonly used Pasquill-Gifford (P-G) type stability classification that uses standard climatological data revealed that the most stable category in the $\mathrm{P}-\mathrm{G}$ scheme is less selective of the strongly stable nights than the radon-based scheme. This leads to significant underestimation of pollutant concentrations on the most stable nights by the $\mathrm{P}-\mathrm{G}$ scheme. 
Applying the radon-based classification scheme to mixing heights estimated from the diurnal radon accumulation time series provided insight to the range of mixing depths expected at the site for each of the four stability classes, with median values increasing from $35 \mathrm{~m}$ a.g.l. under stable conditions to $500 \mathrm{~m}$ a.g.l. for near neutral conditions.

This stability classification technique has the potential to greatly increase our understanding of processes leading to pollution exceedance events in urban centres, and provides a quantitative means of assessing their magnitude. Careful study of trends in urban pollution under the most stable conditions will be critical for assessing potential health impacts on residents, as well as identifying the need for, and evaluating the efficacy of, emissions mitigation strategies.

Acknowledgements. We thank Ot Sisoutham and Sylvester Werczynski at the Australian Nuclear Science and Technology Organisation for their support of the radon measurement program at Richmond. We also acknowledge Alan Betts and Ningbo Jiang at the New South Wales Office of Environment and Heritage for providing the meteorological and urban pollution data, Sue Reid and Mark Emmanuel, of University of Western Sydney, Richmond Campus, for their support of the radon measurement program at Richmond, and NOAA Air Resources Laboratory (ARL), who made available the HYSPLIT transport and dispersion model and the relevant input files for the generation of back-trajectories used in the analysis of data in this paper.

Edited by: Y. Balkanski

\section{References}

Acker, K., Febo, A., Trick, S., Perrino, C., Bruno, P., Wiesen, P., Moller, D., Wieprecht, W., Auel, R., Giusto, M., Geyer, A., Platt, U., and Allegrini, I.: Nitrous acid in the urban area of Rome, Atmos. Environ., 40, 3123-3133, 2006.

Allegrini, I., Febo, A., Pasini, A., and Schiarini, S.: Monitoring of the nocturnal mixed layer by means of particulate radon progeny measurement, J. Geophys. Res., 99, 18765-18777, doi:10.1029/94JD00783, 1994.

Avino, P., Brocco, D., Lepore, L., and Pareti, S.: Interpretation of atmospheric pollution phenomena in relationship with the vertical atmospheric remixing by means of natural radioactivity measurements (radon) of particulate matter, Annali di Chimica, 93, 589-594, 2003.

Azzi, M. and Johnson, G.: Photochemical smog assessment for $\mathrm{NO}_{\mathrm{x}}$ emissions, using an IER-reactive plume technique, in: Proceedings of Clean Air 1994, 12th International Conference of the Clean Air Society of Australia and New Zealand, 1994.

Chambers, S., Williams, A. G., Zahorowski, W., Griffiths, A., and Crawford, J.: Separating remote fetch and local mixing influences on vertical radon measurements in the lower atmosphere, Tellus B, 63, 843-859, doi:10.1111/j.1600-0889.2011.00565.x, 2011.

Chambers, S. D., Hong, S.-B., Williams, A. G., Crawford, J., Griffiths, A. D., and Park, S.-J.: Characterising terrestrial influ- ences on Antarctic air masses using Radon-222 measurements at King George Island, Atmos. Chem. Phys., 14, 9903-9916, doi:10.5194/acp-14-9903-2014, 2014.

Collaud Coen, M., Praz, C., Haefele, A., Ruffieux, D., Kaufmann, P., and Calpini, B.: Determination and climatology of the planetary boundary layer height above the Swiss plateau by in situ and remote sensing measurements as well as by the COSMO-2 model, Atmos. Chem. Phys., 14, 13205-13221, doi:10.5194/acp14-13205-2014, 2014.

Cohen, D. D., Crawford, J., Stelcer, E., and Atanacio, A. J.: Application of positive matrix factorization, multi-linear engine and back trajectory techniques to the quantification of coal-fired power station pollution in metropolitan Sydney, Atmos. Environ., 61, 204-211, 2012.

Corbyn, L.: Future direction of air quality management in NSW, in: "Action for Air", Proceedings of NSW Clean Air Forum, Powerhouse Museum, Sydney, 17 November 2004, 44-48, Department of Environment and Conservation, Sydney, March 2005, ISBN:1741372615, 2005.

Crawford, J., Cohen, D. D., Chambers, S., Williams, A., and Stelcer, E.: Incorporation of Radon-222 as a parameter in ME-2 to improve apportionment of $\mathrm{PM}_{2.5}$ sources in the Sydney region, Atmos. Environ., 80, 378-388, 2013.

Desideri, D., Roselli, C., Feduzi, L., and Assunta Meli, M.: Monitoring the atmospheric stability by using radon concentration measurements: A study in a Central Italy site, J. Radioanal. Nucl. Ch., 270, 523-530, 2006.

Di Carlo, P., Pitari, G., Mancini, E., Gentile, S., and Pichelli, E.: Evolution of surface ozone in central Italy based on observations and statistical model, J. Geophys. Res., 112, D10316, doi:10.1029/2006JD007900, 2007.

Draxler, R. R. and Hess, G. D.: An overview of the HYSPLIT4 modelling system for trajectories, dispersion and deposition, Aust. Meteorol. Mag., 47, 295-308, 1998.

Duc, H., Shannon, I., and Azzi, M.: Spatial distribution characteristics of some air pollutants in Sydney, Math. Comput. Simulat., 54, 1-21, 2000.

Duenas, C., Perez, M., Fernandez, M. C., and Carretero, J.: Radon concentrations in surface air and vertical atmospheric stability of the lower atmosphere, J. Env. Rad., 31, 87-102, 1996.

Febo, A., Perrino, C., and Allegrini, I.: Measurement of nitrous acid in Milan, Italy, by DOAS and diffusion denuders, Atmos. Environ., 30, 3599-3609, 1996.

Foken, T.: 50 years of the Monin-Obukhov similarity theory, Bound.-Layer Meteor., 119, 431-437, 2006.

Fontan, J., Guedalia, D., Druilhet, A., and Lopez, A.: Une method de mesure de la stabilite verticale de l'atmosphere pres du sol, Bound.-Lay. Meteorol., 17, 3-14, doi:10.1007/BF00121933, 1979.

Fujinami, N. and Esaka, S.: Variations in radon 222 daughter concentrations in surface air with atmospheric stability, J. Geophys. Res., 92, 1041-1043, 1987.

Fujinami, N. and Esaka, S.: A simple model for estimating the mixing depth from the diurnal variation of atmospheric ${ }^{222} \mathrm{Rn}$ concentration, Radiat. Prot. Dosim., 24, 89-91, 1988.

Galmarini, S.: One year of ${ }^{222} \mathrm{Rn}$ concentration in the atmospheric surface layer, Atmos. Chem. Phys., 6, 2865-2886, doi:10.5194/acp-6-2865-2006, 2006. 
Gogolak, C. V. and Beck, H. L.: Diurnal variations of radon daughter concentrations in the lower atmosphere, Natural Radiation Environment III, 1, 259-280, 1980.

Grange, S. K., Salmond, J. A., Trompetter, W. J., Davy, P. K., and Ancelet, T.: Effect of atmospheric stability on the impact of domestic wood combustion to air quality of a small urban township in winter, Atmos. Environ., 70, 28-38, doi:10.1016/j.atmosenv.2012.12.047, 2013.

Griffiths, A. D., Zahorowski, W., Element, A., and Werczynski, S.: A map of radon flux at the Australian land surface, Atmos. Chem. Phys., 10, 8969-8982, doi:10.5194/acp-10-8969-2010, 2010.

Griffiths, A. D., Parkes, S. D., Chambers, S. D., McCabe, M. F., and Williams, A. G.: Improved mixing height monitoring through a combination of lidar and radon measurements, Atmos. Meas. Tech., 6, 207-218, doi:10.5194/amt-6-207-2013, 2013.

Grossi, C., Arnold, D., Adame, J., López-Coto, I., Bolívar, J., de la Morena, B., and Vargas, A.: Atmospheric ${ }^{222} \mathrm{Rn}$ concentration and source term at El Arenosillo $100 \mathrm{~m}$ meteorological tower in Southwest Spain, Radiat. Meas., 47, 149-162, doi:10.1016/j.radmeas.2011.11.006, 2012.

Guedalia, D., Ntsila, A., Druilhet, A., and Fontan, J.: Monitoring of the atmospheric stability above an urban and suburban site using sodar and radon measurements. J. Appl. Meteorol., 19, 839-848, doi:10.1175/1520-0450(1980)019<0839:MOTASA>2.0.CO;2, 1980.

Gupta, P., Christopher, S. A., Box, M. A., and Box, G. P.: Multi year satellite remote sensing of particulate matter air quality over Sydney, Australia, Int. J. Remote Sens., 28, 4483-4498, 2007.

Hart, M., De Dear, R., and Hyde, R.: A synoptic climatology of tropospheric ozone episodes in Sydney, Australia, Int. J. Climatol., 26, 1635-1649, 2006.

Hawke, G. S. and Iverach, D.: A study of high photochemical pollution days in Sydney, N.S.W., Atmos. Environ., 8, 597-608, 1974.

Hinkley, J. T., Bridgman, H. A., Buhre, B. J. P.; Gupta, R. P., Nelson, P. F., and Wall, T. F.: Semi-quantitative characterisation of ambient ultrafine aerosols resulting from emissions of coal fired power stations, Sci. Total Environ., 391, 104-113, 2008.

Jacob, D. J., Prather, M. J., Rasch, P. J., Shia, R.-L., Balkanski, Y. J., Beagley, S. R., Bergmann, D. J., Blackshear, W. T., Brown, M., Chiba, M., Chipperfield, M. P., de Grandpré, J., Dignon, J. E., Feichter, J., Genthon, C., Grose, W. L., Kasibhatla, P. S., Köhler, I., Kritz, M. A., Law, K., Penner, J. E., Ramonet, M., Reeves, C. E., Rotman, D. A., Stockwell, D. Z., van Velthoven, P. F. J., Verver, G., Wild, O., Yang, H., and Zimmermann, P.: Evaluation and intercomparison of global atmospheric transport models using ${ }^{222} \mathrm{Rn}$ and other short-lived tracers, J. Geophys. Res., 102, 5953-5970, 1997.

Jacobi, W. and André, K.: The vertical distribution of radon 222, radon 220 and their decay products in the atmosphere, J. Geophys. Res., 68, 3799-3814, 1963.

Jenner, S. L. and Abiodun, B. J.: The transport of atmospheric sulfur over Cape Town, Atmos. Environ., 79, 248-260, 2013.

Ji, D., Wang, Y., Wang, L., Chen, L., Hub, B., Tang, G., Xin, J., Song, T., Wen, T., Sun, Y., Pan, Y., and Liu, Z.: Analysis of heavy pollution episodes in selected cities of northern China, Atmos. Environ., 50, 338-348, 2012.

Kataoka, T., Yunoki, E., Shimizu, M., Mori, T., Tsukamoto, O., Ohhashi, Y., Sahashi, K., Maitani, T., Miyashita, K., Fujikawa, Y., and Kudo, A.: Diurnal Variation in Radon Concentration and Mixing-Layer Depth, Bound.-Lay. Meteorol., 89, 225-250, 1998.

Kondo, H., Murayama, S., Sawa, Y., Ishijima, K., Matsueda, H., Wada, A., Sugawara, H., and Onogi, S.: Vertical Diffusion Coefficient under Stable Conditions Estimated from Variations in the Near-Surface Radon Concentration, J. Meteorol. Soc. Jpn., 92, 95-106, doi:10.2151/jmsj.2014-106, 2014.

Lambert, G., Polian, G., Sanak, J., Ardouin, B., Buisson, A., Jegou, A., and le Roulley, J. C.: Cycle du radon et de ses descentants: application à l'étude des échanges troposphère-stratosphère, Ann. Géophys., 38, 497-531, 1982.

Leach, V. A. and Chandler, W. P.: Atmospheric dispersion of radon gas and its decay products under stable conditions in arid regions of Australia, Environ. Monit. Assess., 20, 1-17, 1992.

Leighton R. M. and Spark E.: Relationship between synoptic climatology and pollution events in Sydney, Int. J. Biometeorol., 41, 76-89, 1997.

Leslie, L. M. and M. S. Speer: Preliminary modelling results of an urban air quality model verifying the prediction of nitrogen dioxide, sulphur dioxide and ozone over the Sydney basin, Meteorol. Atmos. Phys., 87, 89-92, doi:10.1007/s00703-003-0062-7, 2004.

Liu, X., Gao, N., Hopke, P. K., Cohen, D. D., Bailey, G., and Crisp, P.: Evaluation of spatial patterns of fine particle sulphur and lead concentrations in New South Wales, Australia, Atmos. Environ., 30, 9-24, 1996.

Mahrt, L.: Stratified atmospheric boundary layers, Bound.-Lay. Meteorol, 90, 375-396, 1999.

Malakhov, S. G., Bakulin, V. N., Dmitrieva, G. V., Kirichenko, T. V., Sisigina, T. I., and Starikov, B. G.: Diurnal variation of radon and thoron decay product concentrations in the surface layer of the atmosphere and their washout by precipitation, Tellus, 18, 643-654, 1966.

Moses, H., Stehney, A. F., and Lucas, H. F.: The effect of meteorological variables upon the vertical and temporal distribution of atmospheric radon, J. Geophys. Res., 65, 1223-1238, 1960.

Pasini, A. and Ameli, F.: Radon short range forecasting through time series preprocessing and neural network modelling, Geophys. Res. Lett., 30, 1386, doi:10.1029/2002GL016726, 2003.

Pasquil, D.: The estimation of the dispersion of windborne material, The Meteorological Magazine, 90, 33-49, 1961.

Pasquill, F. and Smith, F. B.: Atmospheric Diffusion, 3rd edition, Ellis Horwood Ltd., Chichester, 437 pp., 1983.

Perrino, C., Pietrodangelo, A., and Febo, A.: An atmospheric stability index based on radon progeny measurements for the evaluation of primary urban pollution, Atmos. Environ., 35, 52355244, 2001.

Perrino, C., Catrambone, M., and Pietrodangelo, A.: Influence of atmospheric stability on the mass concentration and chemical composition of atmospheric particles: a case study in Rome, Italy, Environ Int., 34, 621-628, doi:10.1016/j.envint.2007.12.006, 2008

Pitari, G., Coppari, E., De Luca, N., and Di Carlo, P.,: Observations and box model analysis of radon-222 in the atmospheric surface layer at L'Aquila, Italy: March 2009 case study, Environ. Earth Sci., 71, 2353-2359, 2014.

Porstendörfer, J., Butterweck, G., and Reineking, A.: Diurnal variation of the concentrations of radon and its short-lived daughters in the atmosphere near ground, Atmos. Environ., 3, 709-713, 1991. 
Schery, S. D. and Huang, S.: An estimate of the global distribution of radon emissions from the ocean, Geophys. Res. Lett., 31, L19104, doi:10.1029/2004GL021051, 2004.

Sesana, L., Caprioli, E., and Marcazzan, G. M.: Long period study of outdoor radon concentration in Milan and correlation between its temporal variations and dispersion properties of atmosphere, J. Environ. Radioactiv., 65, 147-160, doi:10.1016/S0265-931X(02)00093-0, 2003.

Sesana, L., Ottobrini, B., Polla, G., and Facchini, U.: ${ }^{222} \mathrm{Rn}$ as indicator of atmospheric turbulence: measurements at Lake Maggiore and on the pre-Alps, J. Environ. Radioactiv., 86, 271-288, doi:10.1016/j.jenvrad.2005.09.005, 2006.

Stull, R. B.: An Introduction to Boundary Layer Meteorology, Springer, New York, 666 pp., 1988.

Turekian, K. K., Nozaki, Y., and Benninger, L. K.: Geochemistry of atmospheric radon and radon products, Ann. Rev. Earth Planet. Sci., 5, 227-255, 1977.

Turner, B.: A diffusion model for an urban area, J. Appl. Meteorol., 3, 83-91, 1964.

USEPA: Guidance on the Use of Models and Other Analyses for Demonstrating Attainment of Air Quality Goals for Ozone, $\mathrm{PM}_{2.5}$, and Regional Haze, United States Environmental Protection Agency, EPA-454/B-07-002, Research Triangle Park, North Carolina, 2007.

Veleva, B., Valkov, N., Batchvarova, E., and Kolarova, M.: Variation of short-lived beta radionuclide (radon progeny) concentrations and the mixing processes in the atmospheric boundary layer, J. Environ. Radioactiv., 101, 538-543, 2010.
Venkatram, A.: An examination of the Pasquill-Gifford-Turner dispersion scheme, Atmos. Environ., 30, 1283-1290, 1996.

Wang, F., Zhang, Z., Ancora, M. P., Deng, X., and Zhang, H.: Radon natural radioactivity measurements for evaluation of primary pollutants, The Scientific World Journal, 5, 626989 , doi:10.1155/2013/626989, 2013.

Whittlestone, S. and Zahorowski, W.: Baseline radon detectors for shipboard use: development and deployment in the First Aerosol Characterization Experiment (ACE 1), J. Geophys. Res., 103, 16743-16751, doi:10.1029/98JD00687, 1998.

Wilkening, M. H. and Clements, W. E.: Radon-222 from the ocean surface, J. Geophys. Res., 80, 3829-3830, 1975.

Williams, A. G., Chambers, S. D., and Griffiths, A.: Bulk Mixing and Decoupling of the Nocturnal Stable Boundary Layer Characterized Using a Ubiquitous Natural Tracer, Bound.-Lay. Meteorol., 149, 381-402, doi:10.1007/s10546-013-9849-3, 2013.

Xia, Y., Conen, F., Haszpra, L., Ferenczi, Z., and Zahorowski, W.: Evidence for nearly complete decoupling of very stable nocturnal boundary layer overland, Bound.-Lay. Meteorol., 138, 163-170, 2011.

Zhang, Z., Wang, F., Costabile, F., Allegrini, I., Liu, F., and Hong, W.: Interpretation of ground-level ozone episodes with atmospheric stability index measurement, Environ. Sci. Pollut. Res., 19, 3421-3429, doi:10.1007/s11356-012-0867-3, 2012. 